\title{
Evaluación de Riesgos Laborales y Propuesta de un Plan de Prevención de Riesgos y Emergencias en Centros de Salud Pública (CSP)
}

\section{Gustavo Efraín Carrera Oña, MsC, Investigador José Omar Cabrera Escobar, $\mathrm{MsC}$}

Docente de Tiempo Completo de la Facultad de Ciencias Pecuarias Escuela Superior Politécnica de Chimborazo (ESPOCH), Ecuador

\section{Medina Cuenca Cristian Iván, Ing., Investigador}

Facultad de Mecánica, Carrera Industrial

Escuela Superior Politécnica de Chimborazo (ESPOCH), Ecuador

Isidoro Enrique Tapia Segarra, $\mathrm{MsC}$

Docente de Tiempo Completo de la Facultad de Informática y Electrónica

Escuela Superior Politécnica de Chimborazo (ESPOCH), Ecuador

\section{Darío Fernando Guamán Lozada, MsC \\ Vinicio Paredes Peralta, $\mathrm{MsC}$}

Docente de Tiempo Completo de la Facultad de Ciencias Pecuarias Escuela Superior Politécnica de Chimborazo (ESPOCH), Ecuador

Doi: 10.19044/esj.2019.v15n18p216 URL:http://dx.doi.org/10.19044/esj.2019.v15n18p216

\section{Resumen}

El presente trabajo verifica el cumplimiento técnico legal en materia de seguridad y salud en el trabajo, así como la identificación y valoración de los factores de riesgos más influyentes en los puestos de trabajo del Centro de Salud del Parque Industrial - IESS de la ciudad de Riobamba. Una vez realizada la inspección en los puestos de trabajo de las instalaciones y el análisis de los factores de riesgos de trabajo de cada puesto mediante la Guía Técnica Colombiana (GTC45), se realizó el plan de prevención de riesgos en el que se propuso: Implementar y adecuar la infraestructura, puestos de trabajo, protocolos de procedimiento, señalética vertical de seguridad y equipos contra incendios, EPP's, brigadas de emergencia y seguimientos periódicos mediante hojas de verificación; generando como resultado una reducción del índice de riesgos laborales un $27 \%$, adicionalmente la propuesta de implementación y reubicación de equipos y la conformación de brigadas en el modular del centro de salud mejora el tiempo de evacuación de 17 a 6 minutos, es decir una reducción del 64,7\%, concluyéndose que el plan de 
prevención de riesgos es rentable para disminuir considerablemente el riesgo laboral.

Palabras clave: Seguridad Laboral, Factores de Riesgo, Prevención de Riesgos, Plan de prevención

\title{
Evaluation of Occupational Risks and Proposal of a Prevention Plan in the Health Center of the Industrial Park - IESS - Riobamba
}

\section{Gustavo Efraín Carrera Oña, MsC, Investigador José Omar Cabrera Escobar, MsC}

Docente de Tiempo Completo de la Facultad de Ciencias Pecuarias Escuela Superior Politécnica de Chimborazo (ESPOCH), Ecuador

\section{Medina Cuenca Cristian Iván, Ing., Investigador}

Facultad de Mecánica, Carrera Industrial

Escuela Superior Politécnica de Chimborazo (ESPOCH), Ecuador

Isidoro Enrique Tapia Segarra, $\mathrm{MsC}$

Docente de Tiempo Completo de la Facultad de Informática y Electrónica

Escuela Superior Politécnica de Chimborazo (ESPOCH), Ecuador

Darío Fernando Guamán Lozada, MsC

Vinicio Paredes Peralta, $\mathrm{MsC}$

Docente de Tiempo Completo de la Facultad de Ciencias Pecuarias

Escuela Superior Politécnica de Chimborazo (ESPOCH), Ecuador

\begin{abstract}
This work verifies the legal technical compliance in matters of safety and health at work, as well as the identification and assessment of the most influential risk factors in the jobs of the Health Center of the Industrial Park - IESS of the city of Riobamba. Once the inspection in the work stations of the facilities and the analysis of the risk factors of work of each position through the Colombian Technical Guide (GTC45), the risk prevention plan was carried out in which it was proposed: Implement and adapt the infrastructure, work stations, procedure protocols, vertical safety signage and fire-fighting equipment, EPP's, emergency brigades and periodic follow-ups through verification sheets; generating as a result a reduction of the labor risk index by $27 \%$, additionally the proposal of implementation and relocation of
\end{abstract}


equipment and the formation of brigades in the modular health center improves the evacuation time from 17 to 6 minutes, that is, a reduction of $64.7 \%$, concluding that the risk prevention plan is profitable to reduce labor risk considerably.

Keywords: Occupational Safety, Risk Factors, Risk Prevention, Prevention Plan

\section{Introduction}

En los primeros años de la industrialización no existía derecho alguno para los trabajadores puesto que, las jornadas laborales duraban más de 15 horas al día, las condiciones de trabajo eran deplorables y la contratación de niños era muy frecuente, además que el 50\% de los trabajadores morían antes de cumplir los 20 años. A partir de 1870 se aplican de alguna manera métodos de protección y se exige implementar derechos para los trabajadores, medidas de seguridad, reducir las horas de trabajo por día y un seguro por los accidentes de trabajo. Después, aproximadamente en 1890 se generaliza en todo el mundo una legislación que protege, de cierto modo, a la sociedad y a los trabajadores frente a los riesgos laborales. Años después, entre 1900 y 1970 se institucionaliza la seguridad y salud ocupacional como una especialidad ya que con varios estudios permitieron mejorar las condiciones de trabajo, el control de riesgos, vigilancia de la salud, además de ciencias como la ergonomía y la medicina ocupacional (Junta de Andalucía, 2011).

En la actualidad la Organización Internacional de Trabajadores (OIT), constituye el organismo regulador de los principios referentes a la seguridad del trabajador desde una visión más integral (OIT, 2019).

En el Ecuador, se han incorporado procesos más exigentes tanto empresas privadas como estatales, mediante el cumplimiento de normas de aplicación de la seguridad industrial a través de varios organismos como el IESS, el Ministerio de Trabajo, entre otros (Chávez Orozco, 2009).

En vista de los avances en el sector de seguridad y salud ocupacional, el Centro de Salud ha adoptado ciertas normas de seguridad, sin embargo, éstas carecen de un estudio técnico en base a las necesidades del establecimiento (Cavassa, 1996 ).

Se ha identificado que en el Centro de Salud del Parque Industrial (CSPI), sus empleados e instalaciones brindan seguridades mínimas, basados en conocimientos empíricos que en muchos de los casos no son los adecuados, poseen conocimientos poco relevantes referente al manejo de un plan de emergencia e instrumentos de protección contra incendios, falta de capacitaciones sobre normas de seguridad, ausencia de un plan de gestión de riesgos, carencia de planes de contingencia frente a desastres o eventos catastróficos, lo que provoca que el personal que labora en la institución, así 
como terceros se encuentren en constante riesgo de sufrir accidentes y enfermedades ocupacionales.

Debido a lo mencionado, se considera urgente la Evaluación y Propuesta de un plan de prevención de riesgos laborales en el centro de salud del parque industrial - IESS de la ciudad de Riobamba, para disminuir el riesgo en los trabajadores y el personal que ingresa a las instalaciones y mejorar las condiciones de trabajo, además de crear una cultura de seguridad y salud ocupacional.

\section{Objetivo General}

Evaluación de riesgos laborales y propuesta de un plan de prevención para el "Centro de Salud del Parque Industrial - IESS" de la ciudad de Riobamba.

\section{Objetivos Específicos}

- Realizar un diagnóstico del estado inicial de la infraestructura del Centro de Salud del Parque Industrial - IESS y cotejarla con los requerimientos de las normativas vigentes.

- Identificar y evaluar los factores de riesgos en cada puesto de trabajo mediante la Guía para la Identificación de los Peligros y la Valoración de los Riesgos en Seguridad y Salud Ocupacional (Guía Técnica Colombiana GTC45, Segunda Edición) en el Centro de Salud del Parque Industrial - IESS.

- Elaborar el plan de prevención de riesgos mediante la normativa legal vigente en base a la evaluación para mitigar los factores de riesgo en el Centro de Salud del Parque Industrial - IESS.

- Elaborar un plan de emergencia y evacuación mediante la normativa legal vigente con respaldo de la Secretaria Nacional de Riesgos para prevenir y responder de manera adecuada ante posibles desastres en el Centro de Salud del Parque Industrial - IESS.

\section{Metodología}

Para prever la seguridad laboral en el centro de salud, el punto de partida fueron los conocimientos referentes a seguridad y salud laboral en el que se utilizó una metodología bibliográfica para la revisión de información en seguridad laboral permitiendo tener una visión panorámica más amplia acerca del objeto de estudio, además se aplicó la metodología descriptiva y deductiva debido a que se obtiene una conclusión a partir de la observación de la situación actual del Centro de Salud del Parque Industrial - IESS. 


\section{Tipo de Investigación}

Por los objetivos fue aplicada ya que, se sustentó en la investigación previamente realizada mediante la identificación de riesgos y con la propuesta del plan prevención de riesgos y emergencias se dio solución al problema. Por el lugar fue de campo, la investigación se ejecutó en el Centro de Salud del Parque Industrial - IESS, ciudad de Riobamba, donde se detectaron los problemas y se pretende solucionar con la propuesta realizada.

Por el nivel fue expresiva y cuasi-experimental, ya que mediante el estudio del problema estableciendo las causas raíz del mismo, se buscó la solución. Por el método fue cuantitativa, ya que los datos observados se procedieron a cuantificarlo de acuerdo a los lineamientos de la norma GTC45.

\section{Métodos de Investigación}

\section{Método inductivo - deductivo}

El método deductivo Es una forma jerárquica de razonar y explicar la realidad partiendo de leyes o teorías generales hacia casos particulares en el que, se pudo emitir conclusiones con conocimientos anteriores en seguridad laboral y las consecuencias que cada una produce en el Centro de Salud del Parque Industrial - IESS.

Se aplicó adicionalmente el método inductivo ya que, es el razonamiento que partió de casos generales a casos particulares. Es decir, fue lo contrario al método deductivo, porque se presenta las definiciones, principios, reglas, fórmulas, de los cuales se extirpan las concernientes terminaciones. Este método fue considerado en el trabajo de investigación ya que se emplearán los pasos definidos del mismo que son: Aplicación, Comprensión y Demostración, puesto que, se plantearon preguntas específicas al inicio de esta investigación y se obtuvieron las conclusiones que se pueden aplicar a otros escenarios parecidos al entorno en el que se desarrolló este trabajo.

\section{Técnicas e instrumentos para la recolección de datos}

Para la recolección de la información se recurrió a la técnica de observación en el que se estudió a las personas en sus actividades de grupo y como miembros de la organización. Con el propósito de analizar y determinar que se está haciendo, como se está haciendo, quien lo hace, cuando se lleva a cabo, cuanto tiempo toma, dónde se hace y por qué se hace, para eso se tomaron en cuenta los siguientes parámetros:

- Determinar las condiciones de trabajo

- Detectar los posibles factores de riesgo

- Detectar condiciones inseguras

- Detectar acciones inseguras

- Medidas preventivas: Fuente, medio y trabajador 


\section{Resultados}

\section{Análisis De La Situación Actual}

El Instituto Ecuatoriano de Seguridad Social es una unidad de atención ambulatoria ubicada en el Parque Industrial edificada en un terreno de 3.360 metros cuadrados, constituyéndose en ofrecer servicios de Salud Integral a la población urbana y rural, a través de personal especializado, aplicando acciones de promoción de la salud, prevención de la enfermedad, recuperación de la salud y rehabilitación, en los servicios de: Pediatría, Ginecología, Medicina General y Familiar, Psicología, Odontología, Enfermería, Farmacia, Laboratorio, Imagenología, Rehabilitación, Trabajo Social, para impulsar ambientes y estilos de vida saludables en la población actual como en la proyección de pobladores a futuro del cantón Riobamba (IESS, 2019).

El Centro de Salud del Parque Industrial no cuenta con un estudio técnico sobre seguridad, así como también carece de un plan de contingencia en caso de presentarse una emergencia, por lo que las personas que laboran en las instalaciones no están preparadas con los medios ni conocimientos necesarios ante una eventualidad de origen natural o antrópica (Medina Cuenca, 2017).

\section{Análisis de la infraestructura}

El análisis de un entorno construido se lo realiza en base a la norma (INEN ISO 24542, 2010), donde se detalla las características y dimensiones mínimas de las edificaciones para determinar que son accesibles y adecuadas. Muchos de los parámetros a analizar son de carácter obligatorio y otras recomendaciones, adaptándolos acorde a las necesidades. En entornos ya construidos se ha de tomar en cuenta las recomendaciones en base a la norma para mejorar la accesibilidad de las instalaciones.

\section{Relación de la edificación con la vía pública}

El establecimiento en sus retiros frontales posee un cerco delantero cuyo objetivo es la de elevar el nivel del acceso a la institución y facilitar la identificación del punto de acceso principal, el mismo que cumple con la especificación de no más de $1.50 \mathrm{~m}$ del nivel de la vereda en base al Art. 11 de la Norma A.010 del (Reglamento Nacional de Edificaciones, 2008), además se encuentra a $8 \mathrm{~m}$ en relación al lindero colindante de la vía pública, así como el acabado del mismo concuerda con la edificación. 


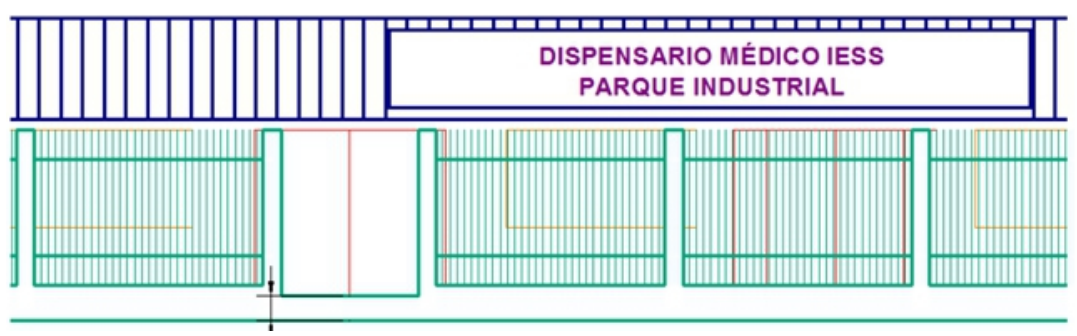

Figura 1. Vista principal del retiro frontal del CSPI Fuente: Autores

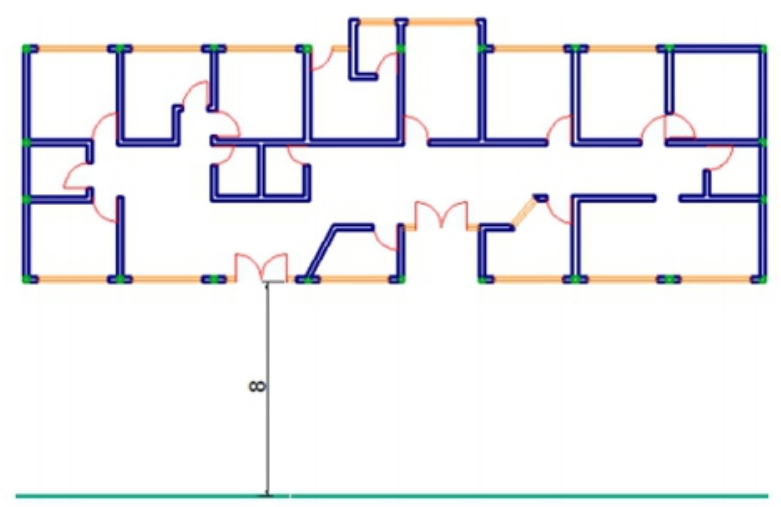

\section{Av. Celso Augusto Rodríguez}

Figura 2. Vista superior del retiro frontal del CSPI Fuente: Autores

\section{Accesos y pasajes de circulación}

El establecimiento cuenta con puertas de acceso, mismas que están bajo (Norma Técnica Ecuatoriana NTE INEN 2 2309:2001, 2013). Tanto las puertas de acceso principal, así como las puertas de ingreso interno cumplen con las dimensiones mínimas acorde a la norma, donde el ancho y altura mínimo son de $0,9 \mathrm{~m}$ y $2.05 \mathrm{~m}$ respectivamente. Sin embargo, las puertas de la institución son de tipo corredizas, por lo que no cumplen con el requisito de apertura hacia afuera, como lo requiere todo establecimiento con concurrencia pública. 


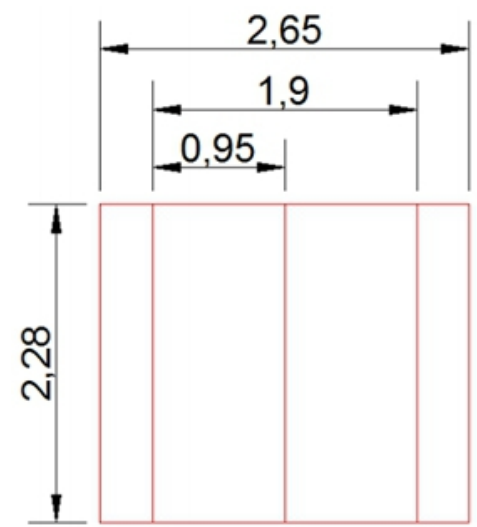

Figura 3. Medidas de la puerta de ingreso principal Fuente: Autores

Además, la instalación cuenta con un punto de acceso (rampa) para personas con discapacidad y movilidad reducida que requieran silla de ruedas para su traslado, la misma que cumple con la (Norma Técnica Ecuatoriana NTE INEN 2 243:2009, 2009), en cuanto a la medida mínima de 1,6 m de ancho y con la (Norma Técnica Ecuatoriana NTE INEN 2 245:2000, 2000) sobre la pendiente de la misma.

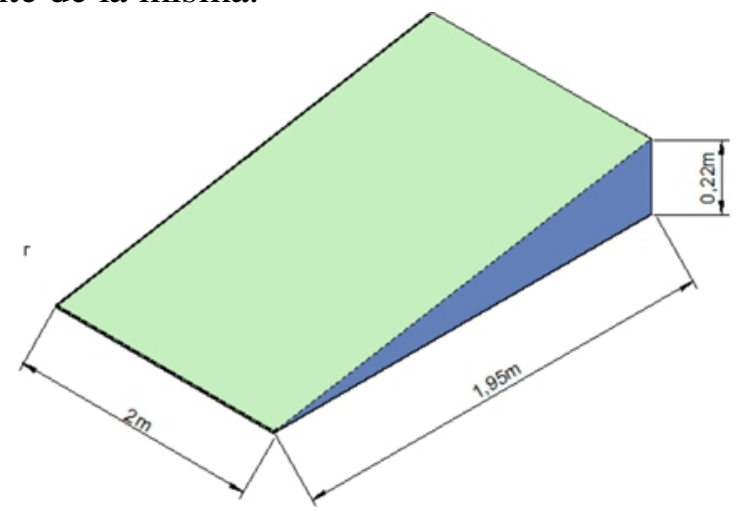

Figura 4. Medidas de la rampa de ingreso para personas con discapacidad Fuente: Autores

$$
\begin{gathered}
P=\text { Altura Longitud } \\
* 100 P=0,22 m 1,95 m \\
* 100 P=11,28 \%
\end{gathered}
$$

En base al valor calculado, éste cumple con la disposición de porcentaje permisible de la pendiente de la rampa de acceso. Más aún, el ingreso desde la vía pública por el retiro frontal no es accesible para estas personas ya que cuando se requiere hacer el ingreso, se lo realiza por el ingreso vehicular, siendo éste un problema ya que las puertas de acceso vehicular se mantienen cerradas durante la jornada laboral. 
Las dimensiones de los pasillos existentes en el establecimiento poseen medidas adecuadas en base a la (Norma Técnica Ecuatoriana NTE INEN 2 247:2000, 2000), donde el espacio mínimo es de 1,2 m.

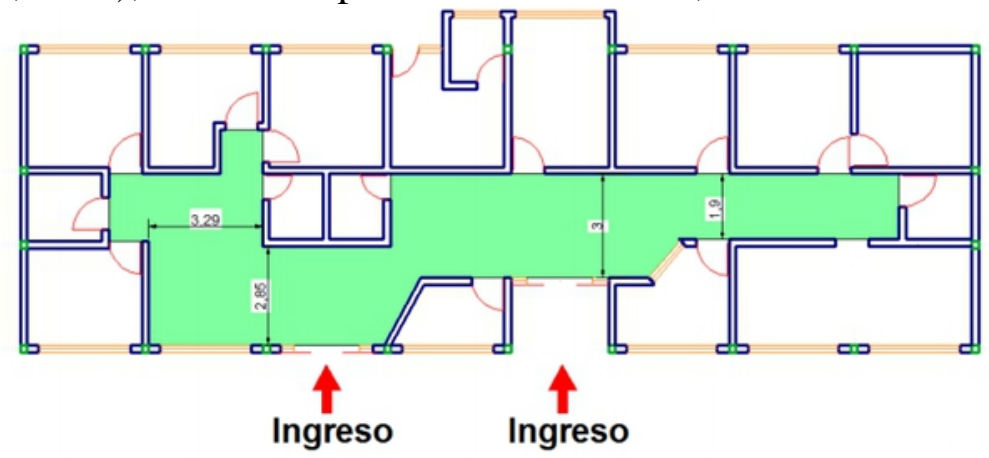

Figura 5. Medidas de los pasillos del CSPI

Fuente: Autores

Dimensiones mínimas de los ambientes. La edificación del centro de salud cumple con la altura mínima de 2,30 m desde el piso al cielo raso según la Norma Técnica A.010 (Reglamento Nacional de Edificaciones, 2008).

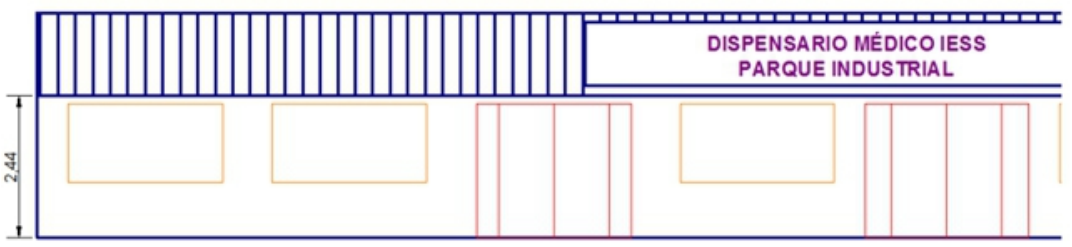

Figura 6. Altura del piso al cielo raso del CSPI

Fuente: Autores

Para el análisis de los riesgos se procederá con la matriz (GTC45, 2010), ya que esta permite la identificación de situaciones de riesgos en base al estudio individual de los factores de generadores del mismo. Este modelo proporciona un método claro y consistente a partir de principios, prácticas y criterios para la implementación de la mejor práctica en la identificación de peligros y la valoración de riesgos. Los lineamientos de la norma (GTC45, 2010) pueden ser tomados como base en el estudio riesgos laborales, y adaptados de acuerdo a la naturaleza, el alcance de las actividades y los recursos establecidos. 
Matriz (GTC45, 2010) aplicada en el Área de Dirección:

Tabla 1. Resultado de riesgos encontrados en Área de Dirección

\begin{tabular}{|c|c|c|c|c|c|c|c|}
\hline Riesgo & $\begin{array}{c}\text { Clasifi } \\
\text { cación }\end{array}$ & Descripción & $\begin{array}{c}\text { Posibles } \\
\text { daños a la } \\
\text { salud }\end{array}$ & $\begin{array}{c}\text { EPP's } \\
\text { Existe } \\
\text { ntes }\end{array}$ & Nivel & $\begin{array}{c}\text { Aceptabilid } \\
\text { ad }\end{array}$ & Valor \\
\hline $\begin{array}{c}\text { Fatiga y } \\
\text { desconcentración } \\
\text { de las actividades }\end{array}$ & $\begin{array}{c}\text { Riesgo } \\
\text { biomec }\end{array}$ & $\begin{array}{c}\text { Movimientos } \\
\text { ánico } \\
\text { puestitivos en el } \\
\text { durante jornajadas } \\
\text { de tiempo } \\
\text { prolongadas }\end{array}$ & $\begin{array}{c}\text { Fatiga, } \\
\text { estrés } \\
\text { laboral }\end{array}$ & - & $\begin{array}{c}\text { Medi } \\
\text { o }\end{array}$ & Aceptable & 60 \\
\hline $\begin{array}{c}\text { Dolor muscular, } \\
\text { cansancio } \\
\text { corporal }\end{array}$ & $\begin{array}{c}\text { Riesgo } \\
\text { biomec } \\
\text { ánico }\end{array}$ & $\begin{array}{c}\text { Postura laboral } \\
\text { prolongada } \\
\text { (sentada) durante } \\
\text { la mayor parte de } \\
\text { la jornada de } \\
\text { trabajo. }\end{array}$ & $\begin{array}{c}\text { Trastornos } \\
\text { músculo- } \\
\text { esquelético } \\
\text { s, fatiga } \\
\text { laboral }\end{array}$ & - & $\begin{array}{c}\text { Medi } \\
0\end{array}$ & Aceptable & 80 \\
\hline
\end{tabular}

Fuente: Autores

Matriz (GTC45, 2010) aplicada en el Área de Servicios Auxiliares:

Tabla 2. Resultado de riesgos encontrados en Área de Servicios Auxiliares

\begin{tabular}{|c|c|c|c|c|c|c|c|}
\hline Riesgo & $\begin{array}{c}\text { Clasifica } \\
\text { ción }\end{array}$ & Descripción & $\begin{array}{c}\text { Posibles } \\
\text { daños a la } \\
\text { salud }\end{array}$ & $\begin{array}{c}\text { EPP's } \\
\text { Existentes }\end{array}$ & Nivel & $\begin{array}{c}\text { Aceptabi } \\
\text { lidad }\end{array}$ & Valor \\
\hline $\begin{array}{l}\text { Enfermeda } \\
\text { des } \\
\text { infectocont } \\
\text { agiosas }\end{array}$ & $\begin{array}{c}\text { Riesgo } \\
\text { biológico }\end{array}$ & $\begin{array}{c}\text { Exposición a } \\
\text { agentes de tipo } \\
\text { patógenos y/o } \\
\text { infectocontagiosos } \\
\text { durante la limpieza } \\
\text { y asepsia en las } \\
\text { diferentes áreas de } \\
\text { la edificación. }\end{array}$ & $\begin{array}{l}\text { Infecciones } \\
\text { bacterianas, } \\
\text { congestiones }\end{array}$ & $\begin{array}{c}\text { Mascarilla, } \\
\text { guantes de } \\
\text { látex, mandil } \\
\text { de } \\
\text { protección, } \\
\text { bata médica }\end{array}$ & $\begin{array}{c}\text { Medi } \\
\text { o }\end{array}$ & $\begin{array}{c}\text { Aceptabl } \\
\mathrm{e}\end{array}$ & 60 \\
\hline $\begin{array}{l}\text { Cortes y } \\
\text { enfermeda } \\
\text { des } \\
\text { infectocont } \\
\text { agiosas }\end{array}$ & $\begin{array}{c}\text { Condicio } \\
\text { nes de } \\
\text { segurida } \\
\text { d }\end{array}$ & $\begin{array}{l}\text { Riesgo de cortes al } \\
\text { manipular objetos } \\
\text { cortopunzantes } \\
\text { como jeringas, } \\
\text { agujas, bisturíes }\end{array}$ & $\begin{array}{c}\text { Exposición a } \\
\text { agentes } \\
\text { biológicos } \\
\text { potencialme } \\
\text { nte } \\
\text { infecciosos } \\
\text { como virus, } \\
\text { bacterias, } \\
\text { protozoos, } \\
\text { hongos o } \\
\text { gusanos }\end{array}$ & $\begin{array}{c}\text { Mascarilla, } \\
\text { guantes de } \\
\text { látex, mandil } \\
\text { de } \\
\text { protección, } \\
\text { bata médica }\end{array}$ & Bajo & $\begin{array}{c}\text { Aceptabl } \\
\mathrm{e}\end{array}$ & 40 \\
\hline $\begin{array}{l}\text { Dolor } \\
\text { muscular, } \\
\text { cansancio } \\
\text { corporal }\end{array}$ & $\begin{array}{c}\text { Riesgo } \\
\text { biomecá } \\
\text { nico }\end{array}$ & $\begin{array}{c}\text { Postura laboral } \\
\text { prolongada (de pie) } \\
\text { durante la mayor } \\
\text { parte de la jornada } \\
\text { de trabajo }\end{array}$ & $\begin{array}{l}\text { Trastornos } \\
\text { músculo- } \\
\text { esqueléticos, } \\
\text { fatiga } \\
\text { laboral }\end{array}$ & - & $\begin{array}{c}\text { Medi } \\
\text { o }\end{array}$ & $\begin{array}{c}\text { No } \\
\text { aceptable }\end{array}$ & 200 \\
\hline
\end{tabular}

Fuente: Autores 
Matriz (GTC45, 2010) aplicada en el Área de Consulta Médica:

Tabla 3. Resultado de riesgos encontrados en Área de Consulta Médica

\begin{tabular}{|c|c|c|c|c|c|c|c|}
\hline Riesgo & $\begin{array}{c}\text { Clasifica } \\
\text { ción }\end{array}$ & Descripción & $\begin{array}{c}\text { Posibles } \\
\text { daños a la } \\
\text { salud }\end{array}$ & $\begin{array}{c}\text { EPP's } \\
\text { Existent } \\
\text { es }\end{array}$ & Nivel & $\begin{array}{c}\text { Aceptabili } \\
\text { dad }\end{array}$ & Valor \\
\hline $\begin{array}{c}\text { Enferme } \\
\text { dades } \\
\text { infectoco } \\
\text { ntagiosas }\end{array}$ & $\begin{array}{c}\text { Riesgo } \\
\text { biológico }\end{array}$ & $\begin{array}{c}\text { Exposición a } \\
\text { microorganismos } \\
\text { patógenos a través } \\
\text { de flujos } \\
\text { corporales, vía } \\
\text { aérea } \\
\end{array}$ & $\begin{array}{l}\text { Infecciones } \\
\text { bacterianas, } \\
\text { congestiones }\end{array}$ & $\begin{array}{l}\text { Mascarill } \\
\text { a de } \\
\text { segurida } \\
\text { d, bata } \\
\text { médica }\end{array}$ & Medio & Aceptable & 60 \\
\hline $\begin{array}{l}\text { Reflectiv } \\
\text { idad } \\
\text { luminosa }\end{array}$ & $\begin{array}{l}\text { Riesgo } \\
\text { ergonómi } \\
\text { co }\end{array}$ & $\begin{array}{l}\text { Puesto de trabajo } \\
\text { con pantalla de } \\
\text { visualización de } \\
\text { datos (PVD), } \\
\text { reflejo de } \\
\text { luminosidad en la } \\
\text { pantalla de } \\
\text { visualización sobre } \\
\text { el médico general }\end{array}$ & $\begin{array}{c}\text { Fatiga visual, } \\
\text { estrés laboral, } \\
\text { dolor de } \\
\text { cabeza }\end{array}$ & - & Medio & Aceptable & 60 \\
\hline
\end{tabular}

Fuente: Autores

Matriz (GTC45, 2010) aplicada en el Área de Odontología:

Tabla 4. Resultado de riesgos encontrados en Área de Odontología

\begin{tabular}{|c|c|c|c|c|c|c|c|}
\hline Riesgo & Clasificación & Descripción & $\begin{array}{c}\text { Posibles } \\
\text { daños a la } \\
\text { salud }\end{array}$ & $\begin{array}{c}\text { EPP's } \\
\text { Existe } \\
\text { ntes }\end{array}$ & Nivel & $\begin{array}{c}\text { Aceptabili } \\
\text { dad }\end{array}$ & Valor \\
\hline $\begin{array}{c}\text { Pérdida } \\
\text { auditiva } \\
\text { progresiv } \\
\text { a }\end{array}$ & Riesgo físico & $\begin{array}{c}\text { Exposición a } \\
\text { ruido constante } \\
\text { de compresor al } \\
\text { momento de } \\
\text { utilizar los } \\
\text { instrumentos } \\
\text { rotatorios en la } \\
\text { remoción y } \\
\text { extracción de } \\
\text { residuos }\end{array}$ & $\begin{array}{c}\text { Reducción de } \\
\text { la capacidad } \\
\text { de las células } \\
\text { ciliadas de } \\
\text { transformar la } \\
\text { vibración en } \\
\text { impulso } \\
\text { nervioso. }\end{array}$ & - & Medi & o & No \\
aceptable & 200 & & \\
\hline $\begin{array}{c}\text { Caídas, } \\
\text { golpes }\end{array}$ & $\begin{array}{c}\text { Riesgo de } \\
\text { tropiezos o } \\
\text { caídas debido la } \\
\text { presencia de } \\
\text { cables del } \\
\text { compresor de } \\
\text { aire en el piso }\end{array}$ & $\begin{array}{c}\text { Esguinces, } \\
\text { torceduras, } \\
\text { luxaciones, } \\
\text { dislocaciones } \\
\text { y/o fracturas } \\
\text { de miembros } \\
\text { superiores e } \\
\text { inferiores }\end{array}$ & - & Alto & No & aceptable & 300 \\
\hline
\end{tabular}

Fuente: Autores 
Matriz (GTC45, 2010) aplicada en el Área de Rayos X:

Tabla 5. Resultado de riesgos encontrados en Área de Rayos X

\begin{tabular}{|c|c|c|c|c|c|c|c|}
\hline Riesgo & $\begin{array}{c}\text { Clasifica } \\
\text { ción }\end{array}$ & Descripción & $\begin{array}{l}\text { Posibles daños a } \\
\text { la salud }\end{array}$ & $\begin{array}{c}\text { EPP's } \\
\text { Existe } \\
\text { ntes }\end{array}$ & Nivel & $\begin{array}{c}\text { Aceptabili } \\
\text { dad }\end{array}$ & Valor \\
\hline $\begin{array}{l}\text { Irritación } \\
\text { de ojos y } \\
\text { quemadu } \\
\quad \text { ras } \\
\text { cutáneas. }\end{array}$ & $\begin{array}{l}\text { Riesgo } \\
\text { físico }\end{array}$ & $\begin{array}{l}\text { Exposición a rayos } \\
\text { X durante el } \\
\text { proceso radiológico } \\
\text { de piezas bucales }\end{array}$ & $\begin{array}{l}\text { Lesión en ojos, } \\
\text { sobre la córnea, el } \\
\text { cristalino o la } \\
\text { retina, y } \\
\text { quemaduras } \\
\text { cutáneas. }\end{array}$ & $\begin{array}{l}\text { Protect } \\
\text { or } \\
\text { delante } \\
\text { ro } \\
\text { plomad } \\
\text { o, } \\
\text { protect } \\
\text { or de } \\
\text { tiroides }\end{array}$ & Alto & $\begin{array}{c}\text { No } \\
\text { aceptable }\end{array}$ & 300 \\
\hline $\begin{array}{l}\text { Alteració } \\
\text { n y } \\
\text { muerte } \\
\text { micro } \\
\text { celular }\end{array}$ & $\begin{array}{l}\text { Riesgo } \\
\text { físico }\end{array}$ & $\begin{array}{c}\text { Exposición a RX } \\
\text { durante y después } \\
\text { de la operación } \\
\text { debido a la } \\
\text { existencia de puesto } \\
\text { de trabajo dentro } \\
\text { del cuarto de RX }\end{array}$ & $\begin{array}{l}\text { Muerte celular, } \\
\text { aberraciones } \\
\text { cromosómicas } \\
\text { transmisibles. } \\
\text { Radiación } \\
\text { colateral } \\
\text { producida por la } \\
\text { radiación UV o la } \\
\text { radiación visible } \\
\end{array}$ & - & $\begin{array}{l}\text { Muy } \\
\text { alto }\end{array}$ & $\begin{array}{c}\text { No } \\
\text { aceptable }\end{array}$ & 1440 \\
\hline
\end{tabular}

Fuente: Autores

Matriz (GTC45, 2010) aplicada en el Área de Enfermería:

Tabla 6. Resultado de riesgos encontrados en Área de Enfermería

\begin{tabular}{|c|c|c|c|c|c|c|c|}
\hline Riesgo & $\begin{array}{c}\text { Clasificaci } \\
\text { ón }\end{array}$ & Descripción & $\begin{array}{c}\text { Posibles } \\
\text { daños a la } \\
\text { salud } \\
\end{array}$ & $\begin{array}{c}\text { EPP's } \\
\text { Existentes }\end{array}$ & $\begin{array}{c}\text { Niv } \\
\text { el }\end{array}$ & $\begin{array}{l}\text { Aceptabi } \\
\text { lidad }\end{array}$ & Valor \\
\hline $\begin{array}{c}\text { Enfermedades } \\
\text { infectosas }\end{array}$ & $\begin{array}{c}\text { Riesgo } \\
\text { biológico }\end{array}$ & $\begin{array}{c}\text { Exposición a } \\
\text { microorganismo } \\
\mathrm{s} \\
\end{array}$ & $\begin{array}{c}\text { Infecciones } \\
\text { bacterianas, } \\
\text { congestiones }\end{array}$ & $\begin{array}{l}\text { Mascarilla, } \\
\text { guantes de }\end{array}$ & $\begin{array}{l}\mathrm{Me} \\
\text { dio }\end{array}$ & $\begin{array}{c}\text { Aceptabl } \\
\mathrm{e}\end{array}$ & 60 \\
\hline Contagiosas & & $\begin{array}{c}\text { patógenos a } \\
\text { través de flujos } \\
\text { corporales, vía } \\
\text { aérea } \\
\end{array}$ & & $\begin{array}{l}\text { látex, bata } \\
\text { médica }\end{array}$ & & & \\
\hline $\begin{array}{c}\text { Cortes y } \\
\text { enfermedades } \\
\text { infectocontagi } \\
\text { osas }\end{array}$ & $\begin{array}{l}\text { Condicion } \\
\text { es de } \\
\text { seguridad }\end{array}$ & $\begin{array}{l}\text { Riesgo de cortes } \\
\text { al manipular } \\
\text { objetos } \\
\text { cortopunzantes } \\
\text { como jeringas, } \\
\text { agujas, bisturíes }\end{array}$ & $\begin{array}{c}\text { Exposición a } \\
\text { agentes } \\
\text { biológicos } \\
\text { potencialment } \\
\text { e infecciosos } \\
\text { como virus, } \\
\text { bacterias, } \\
\text { protozoos, } \\
\text { hongos o } \\
\text { gusanos }\end{array}$ & $\begin{array}{c}\text { Mascarilla, } \\
\text { bata } \\
\text { médica }\end{array}$ & $\begin{array}{c}\text { Alt } \\
\text { o }\end{array}$ & $\begin{array}{c}\text { No } \\
\text { aceptable }\end{array}$ & 1080 \\
\hline
\end{tabular}




\begin{tabular}{|c|c|c|c|c|c|c|c|}
\hline $\begin{array}{l}\text { Afección } \\
\text { pulmonar y } \\
\text { visual }\end{array}$ & $\begin{array}{l}\text { Riesgo } \\
\text { químico }\end{array}$ & $\begin{array}{c}\text { Exposición a } \\
\text { agentes } \\
\text { químicos como } \\
\text { agentes } \\
\text { anestésicos, } \\
\text { óxido de etileno, } \\
\text { hipoclorito de } \\
\text { sodio }\end{array}$ & $\begin{array}{l}\text { Afección } \\
\text { pulmonar, } \\
\text { mareo, } \\
\text { irritación de } \\
\text { los ojos }\end{array}$ & $\begin{array}{c}\text { Protección } \\
\text { respiratoria } \\
\text { (mascarilla } \\
\text { ), } \\
\text { protección } \\
\text { dérmica } \\
\text { (guantes } \\
\text { de látex), } \\
\text { bata } \\
\text { médica } \\
\end{array}$ & $\begin{array}{c}\text { Baj } \\
\text { o }\end{array}$ & $\underset{\mathrm{e}}{\text { Aceptabl }}$ & 100 \\
\hline $\begin{array}{l}\text { Cansancio, } \\
\text { agotamiento } \\
\text { mental }\end{array}$ & $\begin{array}{c}\text { Riesgo } \\
\text { psicosocial }\end{array}$ & $\begin{array}{c}\text { Alta } \\
\text { responsabilidad } \\
\text { en los } \\
\text { procedimientos }\end{array}$ & Estrés laboral & - & $\begin{array}{c}\text { Baj } \\
\text { o }\end{array}$ & $\begin{array}{l}\text { Aceptabl } \\
\mathrm{e}\end{array}$ & 40 \\
\hline $\begin{array}{c}\text { Agotamiento } \\
\text { mental y } \\
\text { visual }\end{array}$ & $\begin{array}{c}\text { Riesgo } \\
\text { biomecáni } \\
\text { co }\end{array}$ & $\begin{array}{c}\text { Minuciosidad en } \\
\text { la tarea }\end{array}$ & $\begin{array}{c}\text { Estrés laboral, } \\
\text { dolor de } \\
\text { cabeza }\end{array}$ & - & $\begin{array}{l}\mathrm{Me} \\
\text { dio }\end{array}$ & $\begin{array}{l}\text { Aceptabl } \\
\mathrm{e}\end{array}$ & 60 \\
\hline $\begin{array}{c}\text { Fatiga y } \\
\text { desconcentraci } \\
\text { ón de las } \\
\text { actividades }\end{array}$ & $\begin{array}{l}\text { Riesgo } \\
\text { biomecáni } \\
\text { co }\end{array}$ & $\begin{array}{l}\text { Movimientos } \\
\text { repetitivos }\end{array}$ & Estrés laboral & - & $\begin{array}{l}\mathrm{Me} \\
\text { dio }\end{array}$ & $\begin{array}{l}\text { Aceptabl } \\
\mathrm{e}\end{array}$ & 60 \\
\hline
\end{tabular}

Fuente: Autores

\section{Análisis de los riesgos mediante fichas técnicas de evaluación}

- Radiaciones iónicas. El 20\% de los ítems no cumplen con los márgenes de seguridad.

- Agentes Biológicos. El 40\% de los ítems no cumplen con los márgenes de seguridad.

- Lugares de trabajo. El 75\% de los ítems no cumplen con los márgenes de seguridad.

- Pantallas de Visualización de Datos (PVD). E1 33,33\% de los ítems no cumplen con los márgenes de seguridad.

- Condición Postural. El 50\% de los ítems no cumplen con los márgenes de seguridad.

- Ruido. El 50\% de los ítems no cumplen con los márgenes de seguridad.

\section{Análisis de riesgos de origen natural}

Los eventos de origen natural son situaciones las cuales no se pueden erradicar, más aún se puede estar preparado.

El nivel de exposición y afectación ante eventos naturales depende en gran manera de la ubicación geográfica, los factores aledaños y la preparación ante estos.

De tal forma, la identificación del riesgo de origen natural en el CSPI es de carácter sísmico y volcánico debido a que éste se encuentra ubicado en una zona de gran actividad volcánica. 


\section{Elaboración y propuesta de plan de riesgos}

Objetivo general. Minimizar la posibilidad de ocurrencia de riesgos laborales presentes en el Centro de Salud mediante propuestas de mejora.

Importancia del plan de riesgos. Los planes de riesgos son parte de la gestión de seguridad laboral, éstos permiten agilizar las acciones preventivas y correctivas en un área de estudio, erradicando o minimizando los riesgos presentes en las instalaciones.

Riesgos laborales. existen ciertos riesgos que no poseen un control adecuado y en caso de no ser tomados en cuenta pueden producir efectos negativos en el personal que labora en las instalaciones, como son:

Se ha identificado que el riesgo con mayor relevancia en el CSPI es el riesgo a exposición de rayos $\mathrm{X}$ debido a la existencia de un puesto de trabajo ajeno al área, por lo que se debe tomar en cuenta es la erradicación o eliminación del puesto de trabajo yacente en el área de rayos X, debido a que no existen formas o medidas de protección hacia el personal que permanece en el área.

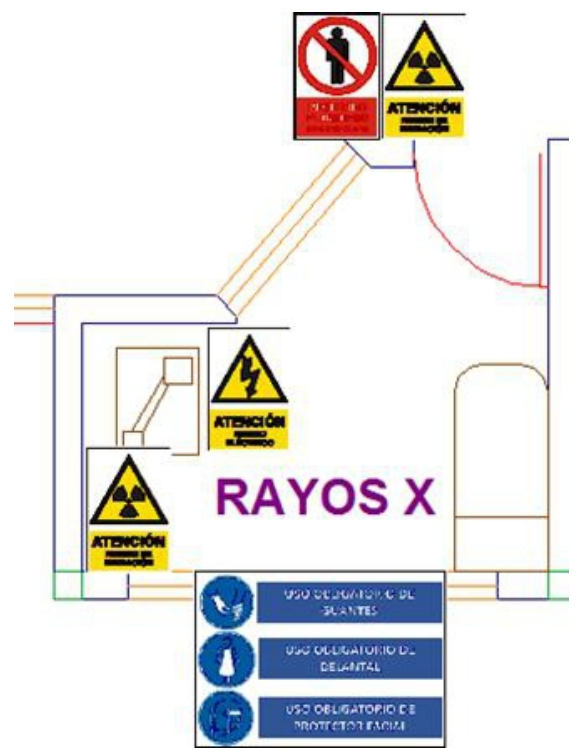

Figura 7. Puesto de trabajo en el área de Rayos X Fuente: Autores

La ubicación actual del dispositivo generador de aire neumático (compresor), el mismo que al encontrarse en el área de odontología genera el riesgo de torceduras, esguinces, luxaciones y/o caídas por los cables de conexión que posee la máquina, los cuales no poseen canaletas de seguridad necesarias adicionalmente también produce ruido y este, como riesgo latente 
también será erradicado, por lo que la reubicación de la maquina neumática elimina dos riesgos de forma inmediata.

En función de la información recabada, espacio e infraestructura y análisis técnico se concluye que el compresor debe ser reubicado y con ello erradicar el riesgo mencionado, a más de implementar un sistema de canalización que permita la correcta conexión del compresor con la maquina odontológica como se muestra en la Figura 8:

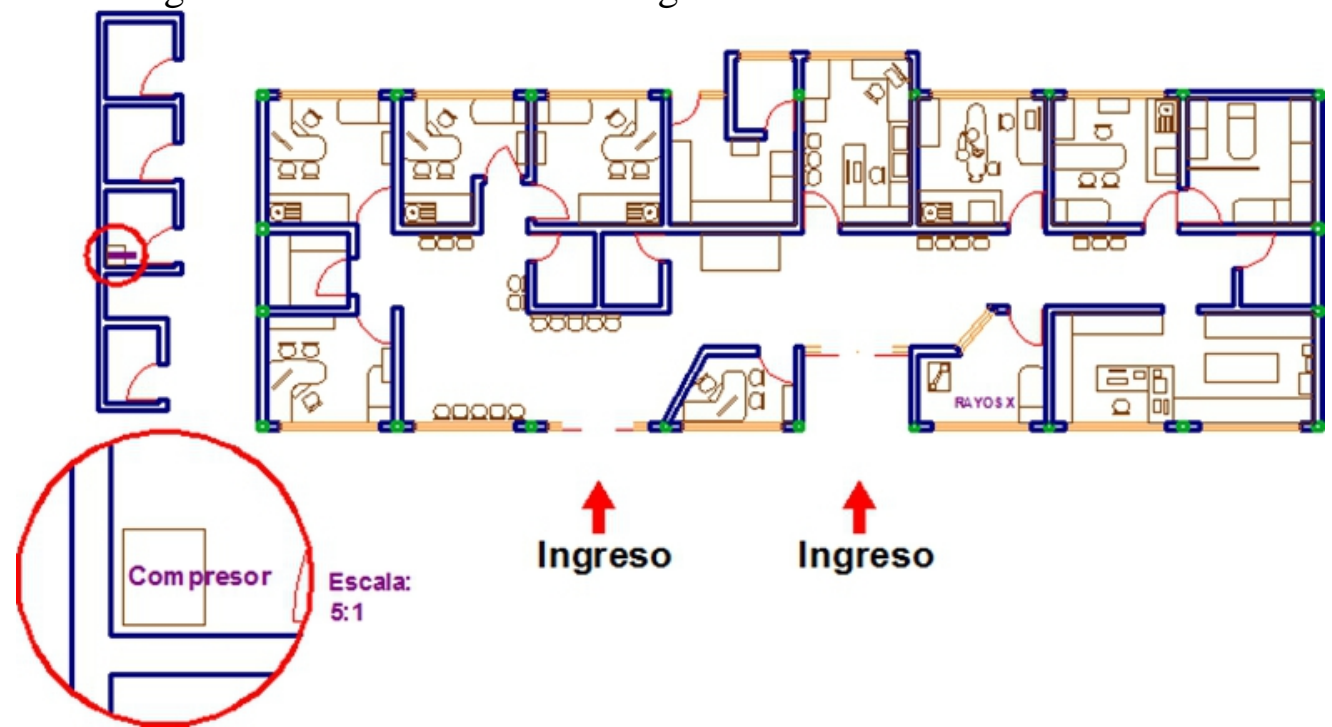

Figura 8. Puesto de trabajo propuesto del área de odontología

Fuente: Autores

La reflectividad luminosa es un factor generador de riesgo visual, debido a la inadecuada posición o ubicación de la pantalla de visualización de datos en las áreas de trabajo, como se puede observar en la Figura 9, por lo que para la minimización de este riesgo se propone una redistribución del área de trabajo como se muestra en la figura 10. 


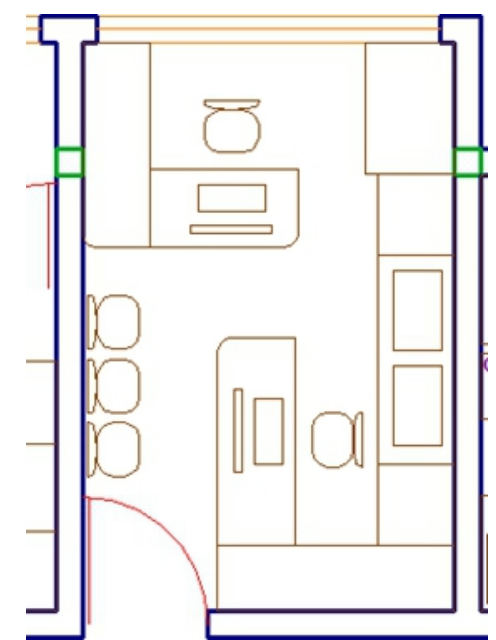

Figura 9. Distribución actual del área de Contabilidad y Costos Fuente: Autor

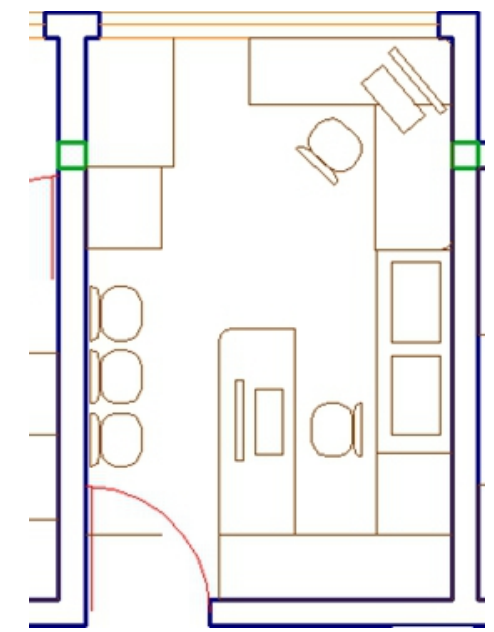

Figura 10. Propuesta de distribución del área de Contabilidad y Costos Fuente: Autor

Postura laboral prolongada, este riesgo incide directamente en el personal de servicios generales, el CSPI cuenta con una persona que realiza estas actividades, y como ya se menciona, esta labor la realiza en su mayoría de tiempo de pie, en vista de ello la persona sufre cansancio, fatiga laboral y/o trastornos músculos-esqueléticos.

Como vía de reducción y control de este riesgo, se propone la implementación de Pasas Activas durante la jornada laboral con el fin mantener un equilibrio entre las actividades respectivas con el cansancio físico y el estrés laboral.

Con la implementación de señalética y la implementación de la propuesta de plan de riesgos se puede mejorar la seguridad laboral un 67\% 
adicional, ya que se eliminaría la exposición a Rayos $\mathrm{X}$ al puesto administrativo evitando la alteración y muerte micro celular, además, de la verificación del correcto uso de las EPP's se reduciría la exposición a cortes, enfermedades infectocontagiosas, caídas y golpes; la redistribución del área de trabajo minimiza la reflectividad disminuyendo la fatiga visual; con la implementación de pausas activas se reduce el dolor muscular y cansancio corporal en el personal y con la reubicación del compresor de aire a una nueva área se reduce la pérdida auditiva progresiva.

\section{Elaboración y propuesta del plan de emergencia}

Objetivo general. Salvaguardar la integridad física del personal y los pacientes, así como del modular del Centro de Salud a través de propuestas de mejoras.

Importancia del plan de emergencia. Los planes de emergencia son parte de la gestión del riesgo de incendio. En caso de presentarse una eventualidad de riesgo, el plan de emergencia contra incendios es la planificación y organización de la institución para el empleo óptimo de los medios de control previstos con el fin de disminuir al máximo las posibles pérdidas humanas y/o materiales.

Cálculo de vías y tiempos de evacuación estimado. En vista de las mejoras a adoptar como plan de propuesta, se procede a realizar un nuevo análisis de las vías y tiempos de evacuación.

Cálculo del tiempo de evacuación. Al igual que en el análisis preliminar, se adoptará un tiempo promedio de un segundo por metro de distancia longitudinal de avance de cualquier persona. El tiempo de detección varía en cuanto al sistema de detección con el que cuente el establecimiento, en el caso actual se propone implementar un sistema de alarma con detectores de humo iónico, el mismo que adoptara un valor de 3 minutos basado en la Figura 11:

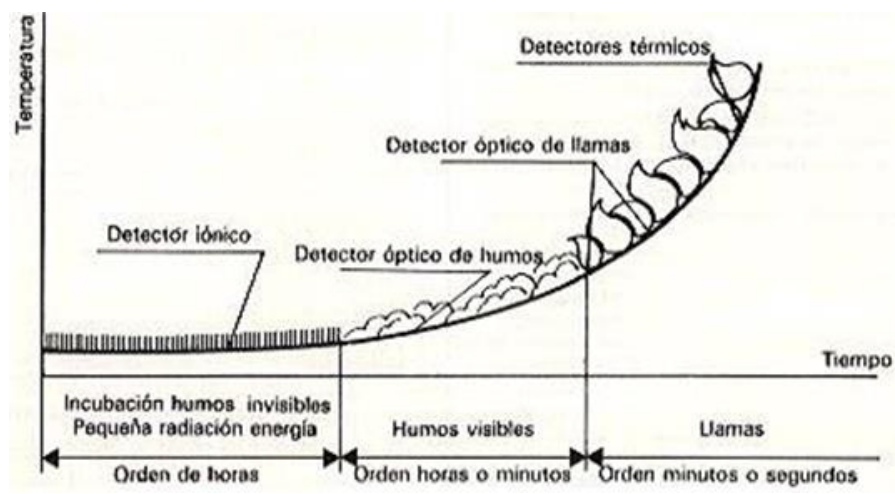

Figura 11. Fase de actuación de detectores

Fuente: (SIAFA, 2003) 
El tiempo de alarma para la notificación del riesgo no deberá sobrepasar el minuto. El tiempo de retardo como ya se mencionó está en función del personal a cargo de liderar la acción inmediata, en cuyo caso con la formación de las brigadas el tiempo adoptado será de un minuto. El tiempo de evacuación radica directamente en el tiempo que requiere una persona en trasladarse desde el punto más alejado de la instalación hasta el punto de salida más cercano, en este caso desde la sala de operaciones hacia la salida 2 (para personas discapacitadas), cuya acción requiere un tiempo aproximado de 30 segundos.

$$
\begin{gathered}
T_{E}=T d+T a+T p+T p e \\
T_{E}=3 \min +1 \mathrm{~min}+1 \mathrm{~min}+20 \mathrm{seg} \\
T_{E}=5 \mathrm{~min} 20 \mathrm{seg} \\
T_{E} \approx 6 \mathrm{~min}
\end{gathered}
$$

El tiempo total para que el personal evacue las instalaciones es de 6 min aproximadamente.

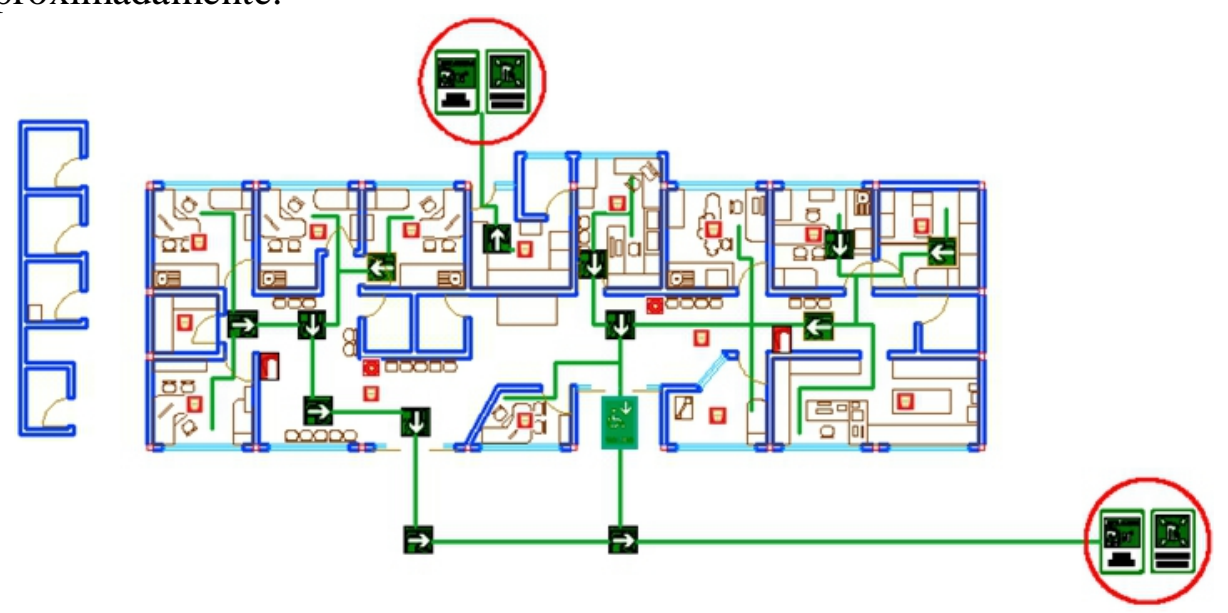

Figura 12. Propuesta de ubicación de los puntos de reunión

Fuente: Autor

Brigadas estructuradas o profesionales. El personal que forma parte de estas brigadas son personal preparadas, con gran experiencia y dedicación en prevención y mitigación de emergencias, y por lo general este tipo de brigadas se establecen en empresas cuyo nivel de riesgo es elevado, a más que el personal de dichas brigadas laboran a tiempo completo en dichas actividades. Asignar tareas y/o responsabilidades a los brigadistas está en función del orden jerárquico de las brigadas, cuyo motivo es el de establecer actividades específicas a cada uno de los participantes, de esta manera la labor 
de prevención y control de emergencias se realizará de forma eficaz, y concisa en el menor tiempo posible precautelando el bienestar personal y colectivo de la institución.

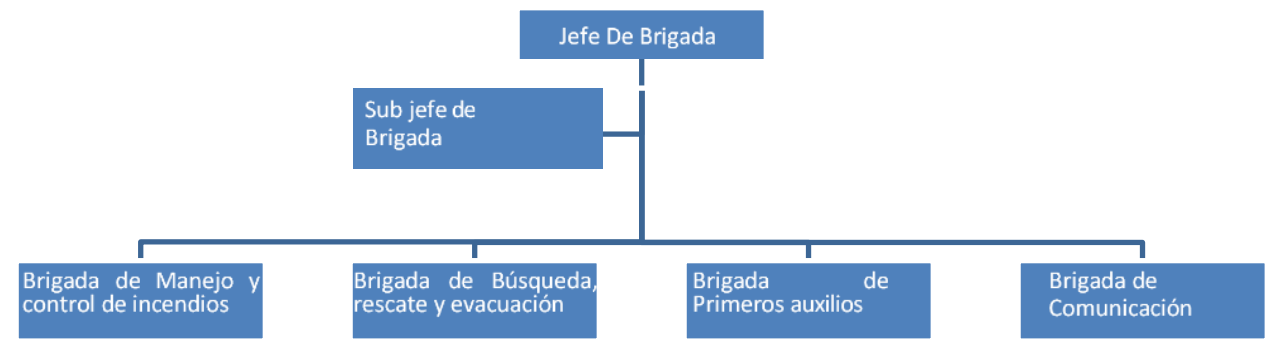

Figura 13. Nivel jerárquico de la Brigada de Emergencia

Fuente: Autor

Procedimientos en caso de emergencia. En cualquier situación de emergencia que se pueda suscitar, se requiere de personas debidamente capacitadas, a más de los equipos y medios de protección establecidos. Las acciones a realizar son:

- Determinar con premura la emergencia y dar la alerta correspondiente.

- La alerta será el punto inicial para iniciar con la evacuación del personal.

- De acuerdo a la magnitud y gravedad del acontecimiento de emergencia se determinará la probabilidad de acción por parte del personal o la intervención de organismos externos.

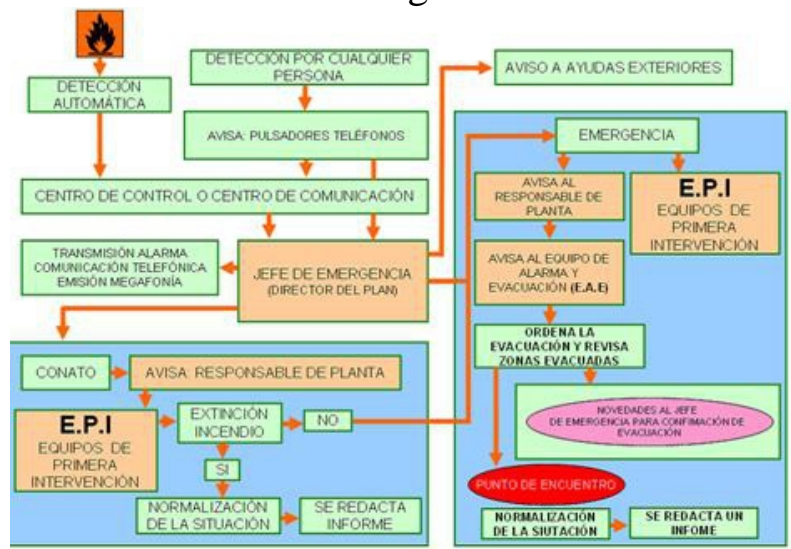

Figura 14. Protocolo de actuación en caso de incendio Fuente: (INSHT, 1983) 
Tabla 7. Cotización de propuesta de plan de prevención de riesgos y emergencia

\begin{tabular}{|c|c|c|c|c|}
\hline \multicolumn{5}{|c|}{ Cotización de EPP } \\
\hline $\mathrm{N}^{\circ}$ & Descripción & Cantidad & Precio por unidad $(\$)$ & Precio total $(\$)$ \\
\hline 1 & Visera protectora contra rayos $\mathrm{X}$ & 1 & 150 & 150 \\
\hline 1 & Guantes protectores contra rayos $\mathrm{X}$ & 1 & 90 & 90 \\
\hline \multicolumn{5}{|c|}{ Cotización Señalética } \\
\hline $\mathrm{N}^{\circ}$ & Descripción & Cantidad & Precio por unidad $(\$)$ & Precio total (\$) \\
\hline 1 & Señalética formato A4 & 72 & 3 & 216 \\
\hline 2 & Señalética formato A2 & 4 & 12 & 48 \\
\hline 3 & Señalética formato $(630 \times 594) \mathrm{mm}$ & 7 & 10 & 70 \\
\hline 4 & $(630 \times 455) \mathrm{mm}$ & 1 & 8 & 8 \\
\hline \multicolumn{5}{|c|}{ Equipo de Protección contra incendio } \\
\hline $\mathrm{N}^{\circ}$ & Descripción & Cantidad & Precio por unidad $(\$)$ & Precio total $(\$)$ \\
\hline 1 & Detector de humo & 15 & 20 & 300 \\
\hline 2 & Alarma contra incendio (sirena) & 2 & 20 & 40 \\
\hline 3 & Pulsador de alarma contra incendio & 2 & 30 & 60 \\
\hline \multicolumn{4}{|r|}{ Total } & 982 \\
\hline
\end{tabular}

Fuente: Autor

\section{Conclusiones}

El Centro de Salud del Parque Industrial (CSPI), no contaba con un estudio técnico de riesgos laborales por lo que se desarrolló una propuesta de prevención para salvaguardar la integridad del personal y las instalaciones.

La infraestructura del Centro de Salud Pública presentó en el estudio técnico de riesgos laborales que sus características y dimensiones cumplen con la normativa vigente, sin embargo, como medida de prevención se propone mantener las puertas de acceso siempre abiertas durante la jornada laboral, así como la adaptación de una rampa de acceso para personas con discapacidad en la vía de acceso del retiro frontal.

En el análisis inicial se determinó que existe un 33\% de riesgos laborales que generan inseguridad en el personal que trabaja en la unidad de atención, los mismos que adoptando la propuesta de mejora se podrían minimizar o erradicar por completo generando así un índice de riesgos de 0 a $5 \%$.

La propuesta del plan de emergencia permitirá planificar, estructurar y organizar los procedimientos a seguir en caso de suscitarse una emergencia mediante la conformación de brigadas.

La propuesta de implementación, reubicación de equipo, señalética contra incendios y conformación de brigadas en el modular del centro de salud mejora el tiempo de evacuación de 17 minutos a 6 minutos, es decir, una reducción del 64,7 \% del tiempo actual aproximadamente. 


\section{Recomendaciones}

Adoptar las propuestas de mejora en cuanto al análisis estructural, riesgos laborales, riesgo de incendio e implantación de señalética y equipo de protección y control mediante la gestión con las autoridades competentes.

Socializar y concientizar sobre los peligros y riesgos a los cuales pueden ser susceptibles en caso de no adoptar las medidas de prevención y protección necesarias, mediante charas, capacitaciones, folletos, etc.

Establecer las brigadas de emergencia en el centro de salud acorde a las directrices mencionadas en el actual trabajo.

Concientizar al personal sobre la importancia de conformación y participación en las brigadas y cumplimiento del plan de emergencia en todo momento, así como la apertura a nuevos conocimientos impartidos en las charlas y capacitaciones.

Dar seguimiento de los posibles peligros y riesgos, así como de la infraestructura, EPP'S, equipo de protección contra incendios y conformación y actualización de las brigadas de emergencia mediante hojas y fichas de verificación generadas en el actual trabajo.

\section{References:}

1. Cavassa, C. R. (1996). Seguridad Industrial: Un enfoque integral. México: Limusa.

2. Chávez Orozco, C. A. (2009). Gestión de la Seguridad y Salud en el Trabajo. Eídos, 13-17.

3. GTC45, G. T. (2010). Guía para la identificación de los Peligros y la valoración de los Riesgos en Seguridad y Salud Ocupacional . Bogotá: ICONTEC.

4. IESS. (2019). Instituto Ecuatoriano de Seguridad Social. Obtenido de Instituto Ecuatoriano de Seguridad Social: https://www.iess.gob.ec/es/inst-quienes-somos

5. INEN ISO 24542. (2010). Servicio Ecuatoriano de Normalización. Obtenido de Servicio Ecuatoriano de Normalización: http://www.normalizacion.gob.ec/

6. INSHT. (1983). Instituto Nacional de Seguridad y Salud en el Trabajo. Obtenido de Instituto Nacional de Seguridad y Salud en el Trabajo: insht.es/vgn-exttemplating/v/index.jsp?vgnextoid...campo=anno...1983

7. Junta de Andalucía. (2011). Nuevos tiempos, nuevos problemas sociales. Educación para personas adultas. Nivel II, 1-26.

8. Medina Cuenca, C. I. (06 de Febrero de 2017). Dspace Espoch. Obtenido de Dspace Espoch: http://dspace.espoch.edu.ec/bitstream/123456789/6863/1/85T00443.p df 
9. Norma Técnica Ecuatoriana NTE INEN 2 2309:2001. (2013). Accesibilidad de las Personas con Discapacidad y Movilidad Reducida al Medio Físico. Espacios de Acceso, Puertas. Quito: INEN.

10. Norma Técnica Ecuatoriana NTE INEN 2 243:2009. (2009). Accesibilidad de las Personas con Discapacidad y Movilidad Reducida al Medio Físico. Vías de Circulación Peatonal. Quito: INEN.

11. Norma Técnica Ecuatoriana NTE INEN 2 245:2000. (2000). Accesibilidad de las personas Al Medio Físico Edificios. Rampas Fija. Quito: INEN.

12. Norma Técnica Ecuatoriana NTE INEN 2 247:2000. (2000). Accesibilidad de las personas al Medio Físico Edificios. Corredores y Pasillos. Características Generales. Quito: INEN.

13. OIT. (10-21 de Junio de 2019). Organización Internacional del Trabajo (OIT). Obtenido de Organización Internacional del Trabajo (OIT): https://www.ilo.org/global/standards/lang--es/index.htm

14. Reglamento Nacional de Edificaciones. (2008). TÍTULO III.1 ARQUITECTURA. NORMA A.010: CONDICIONES GENERALES DE DISEÑO. CAPÍTULO I. Lima: Regional Lima Cap.

15. SIAFA, S. (Abril de 2003). SIAFA Higiene Ocupacional y Medio Ambiente. Obtenido de SIAFA Higiene Ocupacional y Medio Ambiente: http://www.siafa.com.ar/ 